\title{
Psychodynamic psychotherapy for complex trauma: targets, focus, applications, and outcomes
}

This article was published in the following Dove Press journal:

Psychology Research and Behavior Management

8 December 2010

Number of times this article has been viewed

\author{
Deborah Spermon' \\ Yvonne Darlington' \\ Paul Gibney ${ }^{2}$ \\ 'School of Social Work and \\ Human Services, The University of \\ Queensland, St. Lucia, QLD, Australia; \\ ${ }^{2}$ Private Practice, Brisbane, QLD, \\ Australia
}

\begin{abstract}
Complex trauma describes that category of severe, chronic interpersonal trauma usually originating in the formative years of a child. In the adult, this can result in global dissociative difficulties across areas of cognitive, affective, somatic, and behavioral functions. Targeting this field of traumatic pathology, this article reviews the contributions and developments within one broad approach: psychodynamic theory and practice. Brief descriptions of aspects of analytical, Jungian, relational, object relations, and attachment therapeutic approaches are given, along with understandings of pathology and the formulation of therapeutic goals. Major practices within client sessions are canvassed and the issues of researching treatment outcomes are discussed.
\end{abstract}

Keywords: psychodynamic, complex trauma, psychopathology, dissociation, therapy

\section{Introduction}

Trauma in its many guises reappeared in society's awareness in the 1960s and 1970s due to the impacts on returning soldiers from zones of warfare and the emergence of public recognition of the private war zones of violence and maltreatment in homes. ${ }^{1,2}$ Individuals, families, and communities have paid, and are still paying, enormous psychological, social, physical, and financial costs following these events. Since then, trauma categories have been widely explored and a number of therapies have evolved to address the wide array of presentations related to exposure to trauma.

Although psychotherapies began with traditional analytic approaches, later psychodynamic incarnations built upon their foundations and included a focus on intrapsychic, developmental, or relational therapies. Other schools of therapy have also been adapted in their attention to trauma, including cognitive behavioral therapy (CBT) interventions, ${ }^{3}$ and their more recent adaptations of dialectical behavior therapy (DBT) ${ }^{4}$ and eye movement desensitization and reprocessing (EMDR) therapy. ${ }^{5}$ Pharmacotherapy ${ }^{6}$ has had better success with less complex forms of posttraumatic stress disorder (PTSD), while computer technologies using neurofeedback have given initial promising results. ${ }^{7}$

Since the re-emergence of recognition of severe trauma on human development and psychopathology in adults in the 1970s, Chu and Bowman ${ }^{8}$ observed there had been three generations of trauma treatment theory. The first generation of research and response began in the early 1980s and emphasized abreaction of traumatic experience in treatment. Abreaction originated from psychoanalytic traditions and describes the processes of acting out and expressing unconscious conflicts that, in itself, brings relief.
Correspondence: Deborah Spermon PO Box 1083, Woodford, QLD 45I4, Australia

Email rspermon@bigpond.net.au 
The second generation, from the late 1980 s to early 1990 s, developed clearer ideas of the effects of different types of trauma, for example, single incident, adult onset events such as car accidents compared with chronic, interpersonal trauma such as childhood abuse. PTSD described ongoing pathology including the former types of abuse, while complex PTSD described the latter. The global effects of complex trauma across the range of intrapsychic, relational, cognitive, and behavioral functions became a focus. This resulted in recognition of the benefits of employing a number of schools of therapy, and the elaboration of a three-stage model of therapy. This focused first on client safety and stabilization using techniques primarily from $\mathrm{CBT}$, then on processing trauma memories where psychodynamic therapies were utilized, and finally on reconnecting with the wider social environment. $^{9}$

The third generation, from the mid-1990s to 2000, witnessed the attack of the False Memory Syndrome Foundation (FMSF) on therapies focusing on childhood sexual abuse (CSA). The first response was to polarize views, but then it motivated research that refined assessments of trauma pathology including the effects of trauma on memory, and the etiology of adult trauma symptoms, and generally supported the effectiveness of therapy. The focus of therapy changed from uncovering more instances of trauma, to building a more coherent self-narrative.

Since the turn of this century, the field appears to have gained more mainstream acceptance. There has been further research exploring the mechanisms linking cause and effect of trauma and psychopathology, the assessment process, and therapeutic strategies and outcomes. There has been a more sophisticated synthesis of theoretical approaches that honors both the specialization of each, and also their links to the practice context. Concurrently, more practitioners in the field are looking for information on the effects of trauma and trauma therapies to aid clients. A review of the areas of complex trauma and psychodynamic theory, practice, and research is now timely.

\section{Trauma and complex PTSD}

Trauma can be characterized across a number of dimensions: from single incidents to a chronic presence, from natural disasters to experiences of harm inflicted by a significant other without concern for the victim, and from events that occur to a developmentally mature individual to someone much earlier in the lifecycle. Additionally, there are acts of omission such as neglect, or acts of commission such as abuse. Definitions of trauma have variously attempted to capture critical elements that distinguish trauma predicting pathology from malingering and normal challenges that do not lead to significant ongoing maladaptations. The DSM-IV focuses on serious 'physical' harm as its central criterion and ignores patterns of harm, the significance of interpersonal contexts, the differential impact on the very young, and the effects of lack of care as seen in neglect.

Noting the different presentations of clients with extensive histories of severe childhood maltreatment from those who had experienced a single traumatic event as an adult, Herman' coined the term 'complex posttraumatic stress disorder' or 'complex PTSD'. She elaborated an extensive description of six categories of symptoms that has since been adopted by many in the field including van der Kolk et al. ${ }^{10}$ These include alterations in: i) affect regulation, ii) consciousness, iii) self-perception, iv) perception of the perpetrator, v) relations with others, and vi) systems of meaning. The remainder of this article concentrates on this end of the trauma spectrum.

Although the connections between adult pathology and early childhood trauma have long been assumed, ${ }^{11,12}$ the actions of the FMSF and a general call for evidencebased practice triggered research across disciplines including psychology, ${ }^{13,14}$ psychiatry, ${ }^{15,16}$ general medicine, ${ }^{17-19}$ criminal fields, ${ }^{20}$ neurophysiology and neurobiology. ${ }^{21,22}$ These have begun to clarify more specifically what factors, or constellation of traumatic factors, predict patterns of pathology across the lifespan.

An original focus in research was CSA which was linked to later difficulties such as self-injury and eating disorders ${ }^{23,24}$ as well as mental disorders and suicide risk. ${ }^{18,25,26}$ Gold et al ${ }^{13}$ examined elements of CSA and found that the earlier the age of abuse, concurrent multiple perpetrators, and coercive and objectifying sexual acts predicted a greater degree of dissociation in later life.

The description of childhood trauma has been broadened to include physical abuse ${ }^{27}$ and multiple forms of maladaptive family functioning related to neglect and emotional abuse. ${ }^{15,17,19,28,29}$ Attachment styles of early caregivers have also been studied, giving strong support in linking avoidant and disorganized attachment styles to later behavioral problems and dissociation. ${ }^{30,31}$ The Ogawa et al study also connected the age of onset, chronicity, and severity of trauma within these types of relationships to later trauma symptomatology and dissociation. ${ }^{31}$

Across theoretical conceptualizations and research outcomes lies the thread of ongoing patterns of interpersonal 
fear and betrayal, echoing Becker-Blease and Freyd' ${ }^{32}$ view of traumatic stress. As distinct from one-off incidents or occasional failures of relational attunement, these stressors appear to penetrate and overwhelm the undeveloped psyche. They target attacks on 'the coherence, reality testing, and worldview of the victim' (p. 14), ${ }^{33}$ and result in comprehensive dysfunction that can progress into adult life. Chief among these consequences is dissociation.

While the DSM-IV-TR gives a technical classification that defines dissociative disorders as 'a disruption in the usually integrated functions of consciousness, memory, identity, or perception' (p. 519), ${ }^{34}$ Chefetz provides a general working description that can be more easily applied in practice. He said that dissociation is the process whereby 'normally related psychologic experiences and events are detached from each other and result in a distortion of experience with both subtle and profound alterations in interpretation of the meaning of personal and interpersonal events' (p. xvi) ${ }^{35}$ He then gives examples of dissociative phenomena including depersonalization where the person has a sense of detachment from the physical self or being located in the body:

When a person cannot feel their bodily senses, then they can't feel their feelings either; they become emotionally numb,

a hallmark of posttraumatic disorders. Depersonalization can be thought of as a desperate unconscious control mechanism for squelching overwhelming effects like terror, horror, utter helplessness. (p. xvi $)^{35}$

Other phenomena include derealization (the sense that one is separated from the world), amnesia (particularly around traumatic events), splitting into self-states (now under the diagnostic category of dissociative identity disorder (DID)), intrusive affects, and numbing of affect.

\section{Psychodynamic approaches to trauma and dissociation}

Although the origins of psychodynamic therapy are attributed to Freud's psychoanalytic theory with its emphasis on unconscious conflict and meaning, ${ }^{36}$ it has evolved into multistranded approaches exploring various elements of intrapersonal, developmental, and relational processes. A common thread through these, however, is the idea that conflicts are more toxic and less available for integration when they remain unconscious. Therapies addressing trauma use various modalities within the context of the vital therapeutic relationship and the client's developmental history, and attempt to develop client awareness around relationships between defensive dynamics, wishes, and fears, named by Frederickson in 1999 as the 'triangle of conflict' (p. 22). ${ }^{37}$

Psychodynamic approaches have seen controversy from their origins in the late 19th and early 20th centuries. Although theorists began on common ground in proposing the etiology of hysterical pathology (now understood as dissociation) originating in CSA, Freud later broke with this view and developed his intrapsychic theory of defenses and fantasies. This break resulted in a 'false dichotomy' ( $p$. $208)^{38}$ where, for long periods of time, therapists were pressured to choose between understanding etiologies as being primarily intrapsychic or primarily generated from external factors including the objective reality of trauma.

One of the casualties of this split was, ironically, the decades-long relegation of the notion of dissociation to the therapeutic scrap heap. Freud's replacement for dissociation was repression, described as a defense against drives involving the relocation of the relevant conflicts to the unconscious. ${ }^{39}$ This horizontal division into conscious and unconscious differs from dissociative dividedness. Dissociation describes a more vertical splitting where ego states and traumatic memories are 'associatively unavailable to each other' (p. 276).

Although dissociation is a deficit involving the 'integrative functions of memory, consciousness, and identity' ( $p$. $473),{ }^{40}$ it also serves as a protective and survival function for an internal self against overwhelming trauma. ${ }^{39,41}$

The way in which these dissociated parts have been conceived in theory and in practice has inspired a growing number of dynamic approaches, each describing these parts with emphasis on internal defenses, interpersonal interactions, or developmental considerations. In common, however, is a concern in bringing these parts into closer communication, understanding developmental history in some form, and the use of the therapeutic transferential relationship. Although it is beyond the scope of this work to provide a broad review of these theories, their traditions, and their research, examples of each will be described briefly in terms of elements of pathology and formulations of treatment goals. Some applications of these to practice will be discussed in the following section.

\section{Internal defense theories}

Classical psychoanalytic traditions focus on 'resolving pathological defenses and structures' (p. 296), ${ }^{42}$ where a defense is defined as an internal strategy to avoid experiencing 'what they feared would be unbearable pain' (p. 96). ${ }^{43}$ The goal is to facilitate the substitution of primitive defenses such as dissociation with higher order ones such as humor and sublimation. ${ }^{44}$ 
Employing Jung's theory of archetypes and still focusing on the internal world of the client, Kalsched wrote:

... when trauma strikes the developing psyche of a child, a fragmentation of consciousness occurs in which different 'pieces' ... organize themselves according to certain archaic and typical (archetypal) patterns ... one part of the ego regresses to the infantile period, and another progresses, ie, grows up too fast and becomes precociously adapted to the outer world. (p. 3) 41 $^{4}$

Although the function of the progressed part is to 'caretake' the regressed part, the overall result is an ongoing self-traumatization as the caretaker views all comers as potential or actual perpetrators of further trauma. Spontaneous self-expression is held as suspect, and flexibility and creativity become victims. The aim of therapy is an exploration of the intermediate world of experience which symbolically connects internal and external realms, and gives a sense of meaning and coherence to someone once threatened by 'the destruction of the personal spirit' (p. 1).

\section{Interpersonal theories}

Relational psychoanalysts understand that 'the human mind, its normal development, its pathology, and the process of its therapeutic growth are relationally configured' (p. 90). ${ }^{45}$ As such, both the cause and the cure for psychic suffering are found in relationships with others and in relationships between self-states. Although Bromberg believes the normal mind is made up of multiple self-states, those with pathological dissociation lack flexible relationships between these states that give 'a person the remarkable capacity to negotiate character and change simultaneously - to stay the same while changing' (p. 350). The goal of therapy is the facilitation of communication between self-states that have been 'sequestered from each other dissociatively' (p. 359).

Although Gustafson ${ }^{46}$ did not classify himself as a relational psychoanalyst, he understood the central dilemma as social - that of managing the need to fit in with the group alongside the constraints this places on being different. He, borrowing from Balint and others, understood the cause of 'faulted situations' to be primarily early violent intrusions by caregivers or being abandoned and without protection. Employing elements of field theory, Gustafson proposed individuals then developed malignant or benign faults that needed a 'dilemma concept ... to grasp the double jeopardy of these disorders' (p. 8). On one hand, he said the person asking for help can become too relationally close and experience the therapist as a persecutor and betrayer. On the other hand, if the person feels too distant, there is the specter of being condemned to a 'terrible loneliness' that has a 'death aspect' (p. 9). If there is enough space between the horns of this dilemma, therapy is possible and the 'fault' is seen as benign. If there is little or no space, the 'fault' is malignant and successful therapy becomes less likely.

\section{Developmental theories}

In Object Relations theory, early chronic trauma is seen to disrupt the development of understanding the other as a whole, separate being (whole object relations). ${ }^{47-50}$ This results in an incomplete psychic separation of the subject (the individual) from the mother/important other (object). The lack of separation implies an inability to develop more than one perspective. Without a relativity of perspective (no dichotomy between the person of the self/subject and the person of the other/object), there can be no relativity of meaning or ability to symbolize. ${ }^{48}$ Without a capacity to distinguish 'me' from all that is 'not me', boundaries between others, between events, and between times become blurred. This is also reflected 'within' the person who does not develop a differentiation between the psychic mind, the physical body, emotional life, and cognitive capabilities. Although some parts may develop into working units (the physical body and cognitive elements), they remain disconnected from each other. Other aspects, such as emotions and language around emotions, can then bear the brunt of the trauma and function poorly.

Attachment theorists have borrowed heavily from Object Relations as it describes in depth various relationship types that then set the scene for subsequent problems in adult relationships and dissociative symptoms. ${ }^{31,40,51}$ Attachments between a caregiver and an infant can be categorized as 'secure (the infant cries at separation and is quickly comforted at reunion), insecure-avoidant (the infant does not cry at separation and actively avoids the caregiver on reunion), and insecure-ambivalent (the infant cries at separation, but is not easily comforted on reunion)' (p. 472, original italics). ${ }^{40}$ When the infant cannot organize according to any coherent pattern, the attachment is classified as disorganized. It is this style, and that of avoidant, that is linked with dissociation in the adult. ${ }^{31}$ The goal of therapy is the correction of the 'internal working model' (p. 483) the individual experienced as a child, ${ }^{40}$ and developing capacities for secure attachments. ${ }^{13}$ 


\section{Psychodynamic practice applications}

A number of branches of psychodynamic therapy practice have evolved, prioritizing the engagement of clients through relational experiences, dreams and symbolic functioning, or body experience. This growth in alternative entry point practices has been largely due to practice experience where it 'is increasingly clear that patients vary as to the pathways followed toward healing' (p. 575). ${ }^{52}$

Commonalities across these therapies, however, include therapists' use of awareness of their own 'emotional reactions to the patient within the treatment situation' (p. 7), called countertransference..$^{33}$ It has been often remarked that working with clients with complex trauma involves intense countertransferential dynamics, and that these can inform the therapist about re-enactments of such defensive roles as perpetrator, victim, and rescuer replayed within the therapeutic relationship from the original trauma. ${ }^{39,53,54}$ No longer is the therapist the detached observer from classical analytic traditions. Managing these situations in sensitive ways can facilitate client insight and change perceptual understanding, which can then aid in reorganizing responses to the social and psychic worlds.

Making central the therapeutic relationship as the source of recovery, rather than a pathway to it, Bromberg ${ }^{45}$ believed it was the 'reciprocal process of active involvement with the states of mind of the other person that allows a patient's here-and-now perception of self to share consciousness with the experiences of incompatible self-narratives that were formally dissociated' (p. 357, original italics). As the therapist becomes experientially active within the replaying of past trauma events (ie, incompatible self-narratives), communicates his/her reflections on the experience, promotes a continued sense of living through this, and an ability to stay in relational connection with the patient, the patient can develop more spontaneity, flexibility, and 'the wholeness of being human' (p. 357).

Both Freud and Jung used their patients' dreams as a major resource in therapy although Jung understood the purpose of dreams differently from Freud's wish-fulfillment premise. Instead, he thought that dreams pulled together the affects and fragmented experiences of waking life and, using symbolic functions unavailable to consciousness, held these 'pieces together in one dramatic story (that) is a kind of miracle of psychological life which we too easily take for granted. Usually, when dreams do this, no one is listening. In depth psychotherapy, we try to listen' (p. 3). ${ }^{41}$ The idea of engaging a symbolic function in therapy is increasingly found in the literature with authors such as Pestalozzi ${ }^{48}$ and Keinanen ${ }^{49}$ using it to understand the etiology and presentation of trauma psychopathology, as well as in therapy. Others have documented specific applications in therapeutic activity. ${ }^{55,56}$

Another entry point for intervention is a focus on bodily experience. Ogden et al ${ }^{57}$ proposed this 'bottom-up' approach as it addresses 'the more primitive, autonomic, and involuntary functions of the brain' (p. 265). Awareness and integration of emotional expressions and their meanings can then follow. They note there is an 'optimal arousal' range within the system where cognitive, emotional, and sensorimotor information can be integrated. Therefore, therapy is aimed at working within this range and enlarging 'an existing stable and generous window of tolerance' (p. 268).

It is important to note that most authors working in the trauma field share a concern for client safety, particularly as correlations with self-harm and suicide have been established. ${ }^{18,25,26}$ Techniques enabling the client to modulate affective flooding are often included in publications, with Bromberg admonishing practitioners to negotiate a dialectic between 'attunement and confrontation', or 'empathy and anxiety' (p. 288), ${ }^{58}$ that then allows for needs of stability and change to be attended to.

This concern underlines the often complex nature of the client's life context. Both the original trauma and the dysfunctional family environment in which it occurred contribute to enduring difficulties in intimate relationships, ${ }^{29}$ mental ${ }^{59}$ and physical health, ${ }^{19}$ ongoing intergenerational abuse, ${ }^{60}$ and revictimization ${ }^{61}-$ even within the therapeutic relationship. ${ }^{62}$ Clients can come from impoverished backgrounds with interrupted employment histories, have issues of substance abuse, and be the focus of a number of agencies including child safety departments. Intervening in these multiple-risk situations can require care beyond the therapy room.

\section{Outcome evidence: issues in research methodologies}

Research into therapeutic interventions serves many masters. It serves as a vital feedback mechanism for individual practitioners as it assists them in fine-tuning service delivery. In published form, research is valuable in education and scientific inquiry as it questions, explains, and builds theoretical and practice breadth, depth, and sophistication, as well as an evidence base for treatment. Research can also be used in support of legal argument and politically in terms of attracting status and funding in an area of limited resources. 
Although there are numerous methodologies, research broadly falls under quantitative approaches originating in the physical sciences, and qualitative approaches borrowed from the social sciences and humanities. ${ }^{63}$ Using the former paradigm, randomized control trials (RCTs) have been seen as the 'gold standard' of research in recent decades, and therapies such as CBT have flourished as they produce evidence for standardized interventions. Critique of this research method (as opposed to therapies that employ it) has gathered momentum both as it is applied to psychotherapy generally and complex trauma and dissociative pathology specifically. These criticisms fall under the following four categories:

1. The problem of construct validity where the tests employed to measure symptom status do not correspond to the 'theoretically derived constructs currently conceived of as being central to each disorder' (p. 904) ${ }^{64}$

2. The problem of external validity and comorbidity where typical exclusion criteria result in eliminating people with complex pathology; this includes most of those with childhood histories of trauma and dissociation. ${ }^{64-69} \mathrm{To}$ further compound this significant difficulty in generalizability to practice settings, dropout rates through the study period can be as high as $80 \%{ }^{70}$

3. The problem of reducing treatment to ingredients and 'doses' of therapy, privileging measurable elements of skill and cognitive deficits and remedies over process and relational deficits and remedies that take longer time periods. ${ }^{65,66}$

4. RCTs call for a causal analysis rather than a correlational one that would allow for complex constellations of therapistclient treatment variables. That is, the RCT question of comparing reified treatment aspects is different from the practice question of 'are these particular intervention strategies associated with positive outcome' (p. 638). ${ }^{71}$

Given the methodological problems of RCTs raised by the relational/process-focused nature of psychodynamic therapy and the characteristics of complex PTSD, quantitative research in this field is still very limited and in its infancy. After excluding those studies that do not specifically include psychodynamic therapy with adults with complex trauma symptoms or do not separate the schools of therapy from one another (eg, CBT, supportive therapy), only two publications were located. ${ }^{72,73}$ Both these clinical trial studies used psychodynamic-oriented therapy for adult women with psychiatric pathology and histories of childhood abuse, included a control group (the Sachsse study used a waitlist as control), and found that psychodynamic therapy was effective in improving PTSD and other psychiatric symptomatology, interpersonal relationships, and social role functioning. Methodological problems were noted in both publications, including issues of nonrandomization of subjects and high dropout rates.

Traditional psychoanalytic research has employed qualitative methods, often taking the form of case studies. These continue to be valuable in describing constellations of interventions and response, the developing processes across stages, and the intimate interactions between the person of the therapist and the person of the client. Case reports continue in contemporary literature. ${ }^{74-77}$ They do, however, have limitations in generalizing their findings due to nonrandom assignment of patients, single or small number of subjects, lack of experimental control and comparison to other broad treatment conditions, and potential for bias including investigator allegiance effects.

New approaches are being called for to shed light on the elements of effective psychodynamic therapy. Innovative strategies are needed such as that used by Brand et al, ${ }^{78}$ pioneering naturalistic design studying therapy provided by community therapists. This study has given valuable information about the 'state of play' of interventions for this target population as it included descriptions of the constellation of patient, therapist, and treatment conditions across an international sample of 280 patients with dissociative disorders. The results were supportive of community therapies generally, and had the additional advantage of beginning to address cultural differences.

\section{Conclusion}

Within the psychotherapy world, psychodynamic theory and practice have contributed substantially to the understanding and treatment of complex trauma disorders. They have enriched the field with multidimensional views of the personality, the psyche that lies within, and the intersubjective field underpinning therapeutic relationships. They should not stand in competition with other schools; instead, practitioners should look for opportunities to use them in combination and according to the unique needs of the clients they serve.

Perhaps, the next generation of trauma therapy will be successful in attaining official status and gaining space in mainstream manuals such as the upcoming DSM-V. Mainstream acceptance can come with a conservative price tag that subtly reifies and sanitizes the complex nature of personal suffering and traumatic consequences. The call in therapy to address and redress the original conditions that allowed the maltreatment implies an essential element of 
revolution against attitudes contributing to these widespread phenomena. This is both toward the objective social reality of trauma events and within the individual client struggling against what had been a dominant abusive paradigm. This revolutionary attitude should continue to be fostered.

With the advent of objective neuroscientific advances, it seems likely that technologies such as neurofeedback will become more expected in the repertoire of dedicated trauma therapy clinics. As useful as these technologies may be, it is hoped that they do not herald a trend toward more laboratory settings where the client's difficult history and complex present no longer have central place. At present, the trauma literature predominately originates from research practitioners who continue to have firsthand experience of the unique and profound 'black hole of trauma', '79 'forgotten voices', ${ }^{80}$ and the 'island of tortured affect' (p. 407). ${ }^{81}$ They witness their clients' struggles, participate in the emotional journeys of cyclical hope and despair, success and failure, and work toward giving back the name of humanity.

\section{Disclosure}

The authors report no conflicts of interest in this work.

\section{References}

1. Kluft R. Multiple personality disorders. In: Spiegel D, editor. Dissociative Disorders: A Clinical Review. Lutherville (MD): Sidran Press; 1993:17-44.

2. Middleton W. Reconstructing the past: trauma, memory and therapy. Background paper for: Feeling, knowing and being: perspectives on dissociative disorders and treatment. Proceedings of Seminar Convened by the Delphi Centre; 2006 Apr 8-9th; Melbourne.

3. Fine CG. The tactical-integration model for the treatment of dissociative identity disorder and allied dissociative disorders. Am J Psychother. 1999;53(3):361-376.

4. Lineham MM, Tutek D, Heard H, Armstrong H. Interpersonal outcome of cognitive behavioral treatment for chronically suicidal borderline patients. Am J Psychiatry. 1994;151(12):1771-1776.

5. Shapiro F. EMDR treatment: overview and integration. In: Shapiro F, editor. EMDR as an Integrative Psychotherapy Approach: Experts of Diverse Orientations Explore the Paradigm Prism. Washington (DC): American Psychological Association; 2002:27-55.

6. Opler L, Grennan M, Ford J. Pharmacotherapy. In: Courtois C, Ford J, editors. Treating Complex Traumatic Stress Disorders: An EvidenceBased Guide. New York: Guilford Press; 2009:329-349.

7. Keizer AW, Verment RS, Hommel B. Enhancing cognitive control through neurofeedback: a role of gamma-band activity in managing episodic retrieval. Neuroimage. 2010;49(4):3404-3413.

8. Chu JA, Bowman ES. Editorial: trauma and dissociation: 20 years of study and lessons learned along the way. $J$ Trauma Dissociation. 2000;1(1):5-20.

9. Herman J. Trauma and Recovery: From Domestic Abuse to Political Terror. London: Pandora: an imprint of Rivers Oram Press; 1992.

10. van der Kolk B, Roth S, Pelcovitz D, Sunday S, Spinazzola J. Disorders of extreme stress: the empirical foundation of a complex adaptation to trauma. J Trauma Stress. 2005;18(5):389-399.

11. Janet P. Principles of Psychotherapy. Guthrie HM, Guthrie ER, translators. London: George Allen and Unwin Ltd; 1925.
12. Freud S. The aetiology of hysteria. In: Jones E, Riviere J, editors. Sigmund Freud: Collected Papers. Vol. 1. New York: Basic Books; 1896/1959:183-220.

13. Gold S, Hill E, Swingle J, Elfant A. Relationship between childhood sexual abuse characteristics and dissociation among women in therapy. J Fam Violence. 1999;14(2):157-171.

14. Appleyard K, Egeland B, van Dulmen MH, Sroufe L. When more is not better: the role of cumulative risk in child behavior outcomes. J Child Psychol Psychiatry. 2005;46(3):235-245.

15. van der Kolk BA, Pelcovitz D, Roth S, Mandel FS, McFarlane A, Herman JL. Dissociation, somatization, and affect dysregulation: the complexity of adaptation to trauma. Am J Psychiatry. 1996; 153(7):83-93.

16. Chu JA, Frey LM, Ganzel BL, Matthews JA. Memories of childhood abuse: dissociation, amnesia, and corroboration. Am J Psychiatry. 1999;156(5):749-755.

17. van Tilburg MA, Runyan DK, Zolotor AJ, et al. Unexplained gastrointestinal symptoms after abuse in a prospective study of children at risk for abuse and neglect. Ann Fam Med. 2010;8(2):134-140.

18. Cutajar MC, Mullen PE, Ogloff JR, Thomas SD, Wells DL, Spataro J. Suicide and fatal overdose in child sexual abuse victims: a historical cohort study. Med J Austr. 2010;192(4):184-187.

19. Felitti VJ, Anda RF, Nordenberg D, et al. Relationship of childhood abuse and household dysfunction to many of the leading causes of death in adults. The Adverse Childhood Experience (ACE) Study. Am J Prev Med. 1998;14(4):245-258.

20. Moskowitz A, Evans C. Peritraumatic dissociation and amnesia in violent offenders. In: Dell P, O'Neil J, editors. Dissociation and the Dissociative Disorders: DSM-V and Beyond. New York: Taylor and Francis; 2009:197-208.

21. Gorman J, Docherty JP. A hypothesized role for dendritic remodeling in the etiology of mood and anxiety disorders. $J$ Neuropsychiatry Clin Neurosci. 2010;22(3):256-264.

22. Teicher MH, Andersen SL, Polcari A, Anderson CM, Navalta CP, Kim DM. The neurobiological consequences of early stress and childhood maltreatment. Neurosci Biobehav Rev. 2003;27(1-2): 33-44.

23. van der Kolk BA, Perry JC, Herman JL. Childhood origins of selfdestructive behavior. Am J Psychiatry. 1991;148(12):1665-1671.

24. Low G, Jones D, MacLeod A, Power M, Duggan C. Childhood trauma, dissociation and self-harming behaviour: a pilot study. $\mathrm{Br} J \mathrm{Med}$ Psychol. 2000;73(Pt 2):269-278.

25. Andrews G, Gould B, Corry J. Child sexual abuse revisited. Med J Aust. 2002; 176(10):458-459.

26. Peleikis DE, Mykletun A, Dahl A. Current mental health in women with childhood sexual abuse who had outpatient psychotherapy. Eur Psychiatry. 2005;20(3):260-267.

27. Dominguez DV, Cohen M, Brom D. Trauma and dissociation in psychiatric outpatients. Isr J Psychiatry Relat Sci. 2004;41(2): 98-110.

28. McLaughlin KA, Green JG, Gruber MJ, Sampson NA, Zaslavsky AM, Kessler RC. Childhood adversities and adult psychiatric disorders in the national comorbidity survey replication II: associations with persistence of DSM-IV disorders. Arch Gen Psychiatry. 2010;67(2): 124-132.

29. Davis JL, Petretic-Jackson PA, Ting L. Intimacy dysfunction and trauma symptomatolgy: long-term correlates of different types of child abuse. J Trauma Stress. 2001;14(1):63-79.

30. Carlson EA. A prospective longitudinal study of attachment disorganization/disorientation. Child Dev. 1998;69(4):1107-1128.

31. Ogawa JR, Sroufe LA, Weinfield NS, Carlson EA, Egeland B. Development and the fragmented self: longitudinal study of dissociative symptomatology in a nonclinical sample. Dev Psychopathol. 1997;9(4):855-879.

32. Becker-Blease KA, Freyd JJ. Beyond PTSD: an evolving relationship between trauma theory and family violence research. $J$ Interpers Violence. 2005;20(4):403-411. 
33. Dalenberg CJ. Countertransference and the Treatment of Trauma. Washington (DC): American Psychological Association; 2000.

34. American Psychiatric Association. Diagnostic and Statistical Manual of Mental Disorders Text Revision (DSM-IV-TR). Washington (DC): American Psychiatric Association; 2000.

35. Chefetz RA. Preface: why should you read these articles on dissociative process? Psych Clin N Am 2006;29:xv-xxiii.

36. Gullestad SE. Who is 'who' in dissociation? A plea for psychodynamics in a time of trauma. Int J Psychoanal. 2005;86(Pt 3):639-656.

37. Schottenbauer MA, Glass CR, Arnkoff DB, Gray SH. Contributions of psychodynamic approaches to treatment of PTSD and trauma: a review of the empirical treatment and psychopathology literature. Psychiatry. 2008;71(1):13-34.

38. Waugaman R. Multiple personality disorder and one analyst's paradigm shift. Psychoanal Inq. 2000;20(2):207-226.

39. Davies J, Frawley M. Dissociative processes and transferencecountertransference paradigms in the psychoanalytically oriented treatment of adult survivors of childhood sexual abuse. In: Mitchell SA, Aron L, editors. Relational Psychoanalysis: The Emergence of a Tradition. Hillsdale (NJ): Analytic Press; 1999: 271-304.

40. Liotti G. Trauma, dissociation, and disorganized attachment: three stands of a single braid. Psychother Theory Res Pract Train. 2004;41(4):472-486.

41. Kalsched DE. The Inner World of Trauma: Archetypal Defences of the Personal Spirit. London: Routledge; 1996.

42. Kluft R. An overview of the psychotherapy of dissociative identity disorder. Am J Psychother. 1999;53(3):289-319.

43. McWilliams N. Psychoanalytic Diagnosis: Understanding Personality Structure in the Clinical Process. New York: Guilford Press; 1994.

44. Eagle GT. The shattering of the stimulus barrier: the case for an integrative approach in short-term treatment of psychological trauma. J Psychother Integr. 2000;10(3):301-323.

45. Bromberg PM. Truth, human relatedness, and the analytic process: an interpersonal/relational perspective. Int J Psychoanal. 2009; 90(2):347-361.

46. Gustafson J. Brief Versus Long Psychotherapy: When, Why, and How. North Bergen (NJ): Jason Aronson, Inc.; 1995.

47. Buhl C. Eating disorders as manifestations of developmental disorders: language and the capacity for abstract thinking in psychotherapy of eating disorders. Eur Eat Disord Rev. 2002;10(2):138-145.

48. Pestalozzi J. The symbolic and concrete: psychotic adolescents in psychoanalytic psychotherapy. Int $J$ Psychoanal. 2003;84(Pt 3): $733-753$.

49. Keinanen M. The meaning of the symbolic function in psychoanalytic psychotherapy: clinical theory and psychotherapeutic applications. Br Psychol Soc. 1997;70(Pt 4):325-338.

50. Solomon HM. Self creation and the limitless void of dissociation: the 'as if' personality. J Anal Psychol. 2004;49(5):635-656.

51. Lyons-Ruth K, Dutra L, Schuder MR, Bianchi I. From infant attachment disorganization to adult dissociation: relational adaptations or traumatic experiences? Psychiatr Clin North Am. 2006;29(1):63-86.

52. Schore AN. Attachment trauma and the developing right brain: origins of pathological dissociation. In: Dell PF, O'Neil JA, editors. Dissociation and the Dissociative Disorders: DSM-V and Beyond. New York: Taylor and Francis; 2009:107-141.

53. Bromberg PM. Shrinking the tsunami: affect regulation, dissociation, and the shadow of the flood. Contemp Psychoanal. 2008;44(3):329-350.

54. Chefetz RA. Disorder in the therapist's view of the self: working with the person with dissociative identity disorder. Psychoanal Inq. 2000;20(2):305-329.

55. Nilsson D, Wadsby M. Symboldrama, a psychotherapeutic method for adolescents with dissociative and PTSD symptoms: a pilot study. J Trauma Dissociation. 2010;11(3):308-321.

56. Spermon D, Gibney P, Darlington Y. Complex trauma, dissociation, and the use of symbolism in therapy. J Trauma Dissociation. 2009;10(4):436-450.
57. Ogden P, Pain C, Fisher J. A sensorimotor approach to the treatment of trauma and dissociation. Psychiatr Clin North Am. 2006;29(1):263-279.

58. Bromberg PM. Standing in the Spaces: Essays on Clinical Process, Trauma, and Dissociation. Hillsdale (NJ): Analytic Press; 1998.

59. Creamer M, Burgess P, McFarlane A. Post-traumatic stress disorder: findings from the Australian National Survey of mental health and well-being. Psychol Med. 2001;31(7):1237-1247.

60. Hindley N, Ramchandani PG, Jones DP. Risk factors for recurrence of maltreatment: a systematic review. Arch Dis Child. 2006;91(9): 744-752.

61. Cuevas CA, Finkelhor D, Clifford C, Ormrod RK, Turner HA. Psychological distress as a risk factor for re-victimization in children. Child Abuse Negl. 2010;34(4):235-243.

62. Kluft RP. Incest and subsequent revictimization: the case of therapist-patient sexual exploitation, with a description of the Sitting Duck Syndrome. In: Kluft R, editor. Incest-Related Syndromes of Adult Psychopathology. Chicago, IL: American Psychiatric Press, Inc.; 1990:263-287.

63. Maione P, Chenail R. Qualitative inquiry in psychotherapy: research on the common factors. In: Duncan B, Miller S, Hubble M, editors. The Heart and Soul of Change: What Works in Therapy. Washington (DC): American Psychological Association; 1999:57-88.

64. Aikens DE, Hazlett-Stevens H, Craske MG. Issues of measurement and mechanism in meta-analyses: comment on Westen and Morrison (2001). J Consult Clin Psychol. 2001;69(6):904-907.

65. Hinshelwood RD. Commentary: symptoms or relationships. BMJ. 2002;324:292-293.

66. Holmes J. All you need is cognitive behaviour therapy? BMJ. 2002;324(7332):288-290.

67. Lambert MJ. The status of empirically supported therapies: comment on Westen and Morrison's (2001) multidimensional meta-analysis. J Consult Clin Psychol. 2001;69(6):910-913.

68. Nathan PE. Deny nothing, doubt everything: a comment on Westen and Morrison (2001). J Consult Clin Psychol. 2001;69(6):900-903.

69. Spinazzola J, Blaustein M, van der Kolk B. Posttraumatic stress disorder treatment outcome research: the study of unrepresented samples? J Trauma Stress. 2005;18(5):425-436.

70. Brand BL, Classen CC, McNary SW, Zaveri P. A review of dissociative disorders treatment studies. J Nerv Ment Dis. 2009;197(9):646-654.

71. Westen D, Novotny CM, Thompson-Brenner H. The empirical status of empirically supported psychotherapies: assumptions, findings, and reporting in controlled clinical trials. Psychol Bull. 2004;130(4):631-663.

72. Sachsse U, Vogel C, Leichsenring F. Results of psychodynamically oriented trauma-focessed inpatient treatment for women with complex posttraumatic stress disorder (PTSD) and borderline personality diosrder (BPD). Bull Menninger Clin. 2006;70(2):125-144.

73. Vitriol VG, Ballesteros ST, Florenzano RU, Weil KP, Benadof DF. Evaluation of an outpatient intervention for women with severe depression and a history of childhood trauma. Psychiatr Serv. 2009; 60(7):936-942.

74. Kellett $\mathrm{S}$. The treatment of dissociative identity disorder with cognitive analytic therapy: experimental evidence of sudden gains. J Trauma Dissociation. 2005;6(3):55-81.

75. McNevin S, Rivera M. Obsessive compulsive spectrum disorders in individuals with dissociative disorders. $J$ Trauma Dissociation. 2001;2(4):117-131.

76. Kluft R. A clinician's understanding of dissociation: fragments of an acquaintance. In: Dell P, O'Neil J, editors. Dissociation and the Dissociative Disorders: DSM-V and Beyond. New York: Taylor and Francis; 2009:599-623.

77. Sizemore C, Huber R. The twenty-two faces of Eve. Individ Psychol. 1988;44:53-62.

78. Brand B, Classen C, Lanius R, et al. A naturalistic study of dissociative identity disorder patients treated by community clinicians. Psychol Trauma Theory Res Pract Policy. 2009;1:153-171. 
79. van der Kolk B, McFarlane A. The black hole of trauma. In: van der Kolk BA, McFarlane AC, Weisaeth L, editors. Traumatic Stress: The Effects of Overwhelming Experience on Mind, Body and Society. New York: Guilford Press; 1996:3-23.

80. Schwartz H. Dialogues with Forgotten Voices: Relational Perspectives on Child Abuse Trauma and Treatment of Dissociative Disorders. New York: Basic Books; 2000.
81. Bromberg PM. On knowing one's patient inside out: the aesthetics of unconscious communication. Psychoanal Dial. 1991;1(4):399-422.

\section{Publish your work in this journal}

Psychology Research and Behavior Management is an international, peerreviewed, open access journal focusing on the science of psychology and its application in behavior management to develop improved outcomes in the clinical, educational, sports and business arenas. Specific topics covered include: Neuroscience, memory \& decision making; Behavior modification \& management; Clinical applications; Business \& sports performance management; Social and developmental studies; Animal studies. The manuscript management system is completely online and includes a quick and fair peer-review system. Visit http://www.dovepress. com/testimonials.php to read real quotes from published authors.

Submit your manuscript here: http://www.dovepress.com/psychology-research-and-behavior-management-journal 